\title{
AN OBSERVATIONAL STUDY OF EFFICACY OF FNAC IN DIAGNOSING BENIGN AND MALIGNANT SALIVARY NEOPLASM
}

\author{
C. T. Karthikeyan ${ }^{1}$, Magesh Kumar J2 , P. Suresh Babu³, K. Chittbabu4 ${ }^{4}$, K. S. Ravishankar 5 , P. Darwin ${ }^{6}$ \\ ${ }^{1}$ Assistant Professor, Department of General Surgery, Sree Balaji Medical College and Hospital, Chromepet, Chennai. \\ 2 Postgraduate Student, Department of General Surgery, Sree Balaji Medical College and Hospital, Chromepet, Chennai. \\ ${ }^{3}$ Associate Professor, Department of General Surgery, Sree Balaji Medical College and Hospital, Chromepet, Chennai. \\ ${ }^{4}$ Postgraduate Student, Department of General Surgery, Sree Balaji Medical College and Hospital, Chromepet, Chennai. \\ 5 Professor, Department of General Surgery, Sree Balaji Medical College and Hospital, Chromepet, Chennai. \\ ${ }^{6}$ Professor, Department of General Surgery, Sree Balaji Medical College and Hospital, Chromepet, Chennai.
}

\begin{abstract}
\section{BACKGROUND}

Salivary gland tumours are quite uncommon. They constitute about $6 \%$ of all head and neck tumours. A neoplasm in the salivary gland region often presents as a diagnostic challenge with regards to its site of origin and whether it is benign or malignant. Most of these occur in the parotid glands; small percentages occur in the submandibular, sublingual and minor salivary glands. Parotid gland lesions are a histologically diverse group. Tumours of this region comprise $3 \%$ of all head and neck and $0.6 \%$ of all tumours of human body. FNAC of the salivary glands is a commonly accepted sensitive and specific tool in diagnosing benign and malignant salivary neoplasms.(1) The role of Fine Needle Aspiration Cytology (FNAC) for the diagnosis of salivary gland tumours is well documented. Large volume of salivary gland tumours studied by FNAC are being reported in world literature. Its main advantages are that it is safe, simple to do, causes little discomfort to the patient and carries a lesser number of complications. But still there are some diagnostic pitfalls to FNAC due to, 1) Histological complexity and morphological variability of the salivary gland tumours, which make interpretation difficult, 2) Sampling errors, etc. Hence, the effectiveness of FNAC in evaluation of salivary gland tumours is still considered controversial.
\end{abstract}

The main aim of this study is to evaluate the efficacy of FNAC in diagnosing benign and malignant salivary neoplasms.

\section{MATERIALS AND METHODS}

The study was conducted by a retrospective and a prospective analysis of the patients who were admitted in all the surgical units of the Department of General Surgery, Government Stanley Medical College and Hospital, Chennai between January 2010 and November 2011.

Inclusion Criteria - 1) Patients > 13 years old with salivary gland swelling in parotid and submandibular regions, 2) Both male and female sexes.

Exclusion Criteria - 1) Pregnancy, 2) Moribund patients (Liver/renal/cardiac failure patients), 3) Any acute inflammatory condition of the salivary gland, 4) Patients not willing for FNAC/Imaging studies/surgery.

Materials - 1) Fine Needle Aspiration Cytology (FNAC), 2) Imaging Characteristics (Ultrasound, Computed Tomography and Magnetic Resonance Imaging (MRI) of the head and neck region, 3) Surgery, 4) Histopathology report.

Methods - A total of 33 patients with salivary gland lesions who had undergone preoperative FNAC and had been diagnosed by subsequent histopathological examination were included in this study.

\section{RESULTS}

FNAC - Of the 35 cases, FNAC categorised 28 cases (80\%) as neoplastic lesions and 7 (20\%) cases as non-neoplastic lesions. Of the 28 neoplastic cases, FNAC showed 25 cases (89.28\%) to be benign and 3 cases $(10.72 \%)$ to be malignant. HPE report - Of the 35 cases, HPE categorised 28 cases as neoplastic lesions (80\%) and 7 cases (20\%) as non-neoplastic lesions. Of the 28 neoplastic cases, HPE showed 24 cases (85.71\%) to be benign and 4 cases (14.29\%) to be malignant.

\section{CONCLUSION}

Salivary glands are unique in their nature that they are histologically complex and morphologically variable. Unlike neoplasms in other sites where pre-operative biopsy is possible and treatment can be planned based on their reports, biopsy is not recommended in salivary neoplasms, especially parotid because of the fear of tumour spillage and nerve injury. The only acceptable biopsy in a parotid tumour is superficial parotidectomy. FNAC is a cheap, easy, simple and sensitive method for diagnosing salivary neoplasms and these salivary glands are easily accessible to FNAC. Hence, FNAC is being commonly used to diagnose salivary neoplasms.

\section{KEYWORDS}

Salivary Gland, Parotid.

HOW TO CITE THIS ARTICLE: Karthikeyan CT, Kumar MJ, Babu PS, et al. An observational study of efficacy of FNAC in diagnosing benign and malignant salivary neoplasm. J. Evolution Med. Dent. Sci. 2016;5(104):7690-7693, DOI: 10.14260/jemds/2016/1734 
Financial or Other, Competing Interest: None.

Submission 05-10-2016, Peer Review 18-12-2016,

Acceptance 23-12-2016, Published 29-12-2016.

Corresponding Author:

Dr. Magesh Kumar J,

Room No. S21,

Resident Quarters, Block-E,

Sree Balaji Medical College \& Hospital,

Chromepet, Chennai-44.

E-mail: magesh.jeeva7@gmail.com

DOI: $10.14260 /$ jemds/2016/1734

\section{(c) (i) $\odot$}

\section{BACKGROUND}

Salivary gland tumours are quite uncommon. They constitute about $6 \%$ of all head and neck tumours. A neoplasm in the salivary gland region often presents as a diagnostic challenge with regards to its site of origin and whether it is benign or malignant. Most of these occur in the parotid glands; small percentages occur in the submandibular, sublingual and minor salivary glands.

Parotid gland lesions are a histologically diverse group. Tumours of this region comprise $3 \%$ of all head and neck and $0.6 \%$ of all tumours of human body.

FNAC of the salivary glands is a commonly accepted sensitive and specific tool in diagnosing benign and malignant salivary neoplasms.(1) The role of Fine Needle Aspiration Cytology (FNAC) for the diagnosis of salivary gland tumours is well documented. Large volume of salivary gland tumours studied by FNAC are being reported in world literature.

Its main advantages are that it is safe, simple to do causes little discomfort to the patient and carries a lesser number of complications.

\section{But still there are some Diagnostic Pitfalls to FNAC due to}

1. Histological complexity and morphological variability of the salivary gland tumours, which make interpretation difficult.(3)

2. Sampling errors, etc. Hence, the effectiveness of FNAC in evaluation of salivary gland tumours is still considered controversial.

\section{Aim}

The main aim of this study is to evaluate the efficacy of FNAC in diagnosing benign and malignant salivary neoplasms.

\section{MATERIALS AND METHODS}

The study was conducted by a retrospective and a prospective analysis of the patients who were admitted in all the surgical units of the Department of General Surgery, Government Stanley Medical College and Hospital, Chennai between January 2010 and November 2011.

\section{Inclusion Criteria}

1. Patients $>13$ years old with salivary gland swelling in parotid and submandibular regions.

2. Both male and female sexes.

\section{Exclusion Criteria}

1. Pregnancy.

2. Moribund patients (Liver/renal/cardiac failure patients).

3. Any acute inflammatory condition of the salivary gland.

4. Patients not willing for FNAC/Imaging studies/surgery.

\section{Materials}

1. Fine Needle Aspiration Cytology (FNAC).

2. Imaging Characteristics (Ultrasound, Computerised Tomography and Magnetic Resonance Imaging (MRI) of the head and neck region.

3. Surgery.

4. Histopathology report.

\section{Methods}

A total of 33 patients with salivary gland lesions who had undergone preoperative FNAC and had been diagnosed by subsequent histopathological examination were included in this study.

\section{The Study Design is as follows}

1. The FNAC was performed by our Pathology Department using a 23-gauge needle attached to a $10 \mathrm{~mL}$ disposable syringe. Aspirates were smeared on clean slides, wet fixed or air dried and stained by Papanicolaou (PAP) and MayGrunwald-Giemsa (MGG) stains.

2. Based on the initial reports of FNAC, appropriate imaging studies will be done.

3. If the initial FNAC is inconclusive, surgical plan will be based on the clinical and imaging characteristics of the tumour.

4. Patients are then subjected to planned surgical procedure and the specimen will be sent.

\section{RESULTS}

No undue complications due to any interventions (FNAC/imaging modalities/surgery) were encountered during the study period.

The Results of the Study are Displayed as Follows, True Positives

Presence of malignancy correctly diagnosed by FNAC.

\section{True Negatives}

Absence of malignancy correctly diagnosed by FNAC.

\section{False Positives}

Number of cases in which FNAC wrongly diagnosed as malignancy.

\section{False Negatives}

Number of cases in which FNAC failed to diagnose a malignancy.

\section{On Analysing the Available Statistics}

No. of True Positives - 26 (a)

23 cases of pleomorphic adenoma.

01 case of adenoid cystic carcinoma.

02 cases of mucoepidermoid carcinomas as per FNAC report were concordant with the results of the HPE report.

No. of True Negatives - 6 (d)

06 cases of chronic sialadenitis were correctly diagnosed to be non-malignant by FNAC.

\section{No. of False Positives - 1 (b)}

A case of pleomorphic adenoma by FNAC report turned out to be chronic sialadenitis on HPE examination. 
No. of False Negatives - 2 (c)

1. A case of mucoepidermoid carcinoma by HPE report was given a report of pleomorphic adenoma in FNAC.

2. A case of pleomorphic adenoma by HPE report was given a report of sialadenitis in FNAC.

From these Data, the following Results are Obtained by Galen and Gambino Method, i.e.

FNAC's

Sensitivity

$a /(a+c) \times 100,(26 / 28 \times 100)=92.85 \%$

\section{Specificity}

$d /(b+d) \times 100,(6 / 7 \times 100)=85.71 \%$

\section{Positive Predictive Value}

$a /(a+b) \times 100,(26 / 27 \times 100)=96.29 \%$

Negative Predictive Value

$\mathrm{d} /(\mathrm{c}+\mathrm{d}) \times 100,(6 / 8 \times 100)=75 \%$

Diagnostic Accuracy

$(a+d) /(a+b+c+d),(32 / 35 \times 100)=91.42 \%$

\section{Age Distribution}

The age range in our study is 15 to 52 years and the median age is 40 years.

\section{Sex Distribution}

Of the 35 patients, there were 18 males (51.43\%) and 17 females $(48.57 \%)$.

\section{Glands involved as per FNAC Report}

Parotid gland was involved in 25 cases (71.42\%) and submandibular gland in 10 cases (28.58\%).

of the 25 parotid gland involved cases, 22 were benign tumours (pleomorphic adenoma) (88\%) and 3 cases $(12 \%)$ were malignant tumours.

\section{Malignancies Observed in Parotid by FNAC}

Adenoid Cystic Carcinoma - 01 (33.33\%),

Unnamed Malignant Neoplasms - 02 (66.67\%).

Of the 10 submandibular cases, benign tumours were seen in 3 patients (30\%) and 7 patients had non-neoplastic lesions (Sialadenitis) (70\%). No malignancy was observed in submandibular gland. No cases of sublingual and minor salivary gland lesions were encountered during this study.

\section{Glands involved as per HPE Report}

Parotid gland was involved in 25 cases (71.42\%) and submandibular gland in 10 cases $(28.58 \%)$.

Of the 25 parotid gland cases, 21 cases were benign tumours (pleomorphic adenoma) (84\%) and 4 cases (16\%) were malignant tumours.

\section{Malignancies in Parotid as per HPE Report}

Adenoid Cystic Carcinoma - 02 (50\%),

Mucoepidermoid Carcinoma - 02 (50\%).

Of the 10 submandibular cases, benign tumours were seen in $3(30 \%)$ cases and non-neoplastic lesions (chronic sialadenitis) in 7 (70\%) cases. No malignancy was reported in submandibular gland in our study.

\section{Results of FNAC}

Of the 35 cases, FNAC categorised 28 cases ( $80 \%$ ) as neoplastic lesions and 7 (20\%) cases as non-neoplastic lesions. Of the 28 neoplastic cases, FNAC showed 25 cases (89.28\%) to be benign and 3 cases $(10.72 \%)$ to be malignant.

Total no. of neoplastic lesions - 28

\section{Neoplastic Lesions Identified by FNAC}

$\begin{array}{lll}\text { 1. Pleomorphic adenoma } & - & 25 \\ \text { 2. Adenoid cystic carcinoma } & - & 01 \\ \text { 3. Malignant neoplasms } & - & 02 \\ \text { Total no. of non-neoplastic lesions } & - & 07\end{array}$

\section{Non-Neoplastic Lesions Identified by FNAC}

Sialadenitis - 07

Results of Histopathology Examination (HPE) Report

Of the 35 cases, HPE categorised 28 cases as neoplastic lesions $(80 \%)$ and 7 cases $(20 \%)$ as non-neoplastic lesions. Of the 28 neoplastic cases, HPE showed 24 cases (85.71\%) to be benign and 4 cases $(14.29 \%)$ to be malignant.

$\begin{array}{lcc}\text { Total no. of neoplastic lesions } & - & 28 \\ \text { 1. Pleomorphic adenoma } & - & 24 \\ \text { 2. Adenoid cystic carcinoma } & - & 02 \\ \text { 3. Mucoepidermoid carcinoma } & - & 02 \\ \text { Non-neoplastic lesions identified by FNAC } & - & 07\end{array}$

\section{DISCUSSION}

The role of FNAC in the diagnosis of parotid tumours has been well established, as this is a safe and easy diagnostic procedure that causes little discomfort to the patient.(1) The main objective of FNAC in parotid lesions is to differentiate between benign lesions and malignant tumours.(2)

But because of the sampling errors and the histological complexity of the salivary gland tumours, it is being difficult to accurately differentiate between benign and malignant neoplasms.(3),(4)

Our study is done mainly to evaluate the efficacy of FNAC in diagnosing benign and malignant salivary neoplasms. The efficacy is established by calculating the sensitivity, specificity, positive and negative predictive values and diagnostic accuracy of FNAC with respect to Histopathological Examination (HPE) reports.

The sensitivity of FNAC in our study is $92.85 \%$, i.e. ability of FNAC to diagnose salivary gland tumours.

The specificity of FNAC in our study is $85.71 \%$, i.e. the ability of FNAC to identify correctly those who do not have the salivary gland tumours and the diagnostic accuracy of FNAC in our study is $91.42 \%$.

\section{The Causes for False Negatives in our study are explained} as follows

1. A case of mucoepidermoid carcinoma was given a report of pleomorphic adenoma in FNAC. It may be due to the similarity in cytological appearances between the two tumours.

2. A case of pleomorphic adenoma was given a report of sialadenitis in FNAC. It may be due to the sampling error as the area of lesion from where the FNAC was taken might not have been a representative of the tumour.(5) 
The histological complexity and morphological variability of the salivary neoplasms explain the cause for false positives in our study, (1 case of pleomorphic adenoma was diagnosed as sialadenitis in FNAC).

The sensitivity values of FNAC in our study correspond to the published reports in world literature as discussed previously (84\% - 100\%).(6),(7) But the specificity value of FNAC in our study $(85.71 \%)$ tends to be lower than the published literature reports ( $94 \%-100 \%)$. This may be due to the lesser number of cases included in this study and hence this may be considered as the main limitation of this study.

The other details which can be inferred from this study are, most of the salivary gland tumours in our study occur in the age group of 40 years and it is equivocally distributed between males and females.

Parotid gland is commonly involved followed by the submandibular gland. Most of the neoplastic lesions are of benign nature.(8) There were no complications encountered by the patients during our study.

\section{CONCLUSION}

Salivary glands are unique in their nature that they are histologically complex and morphologically variable. Unlike neoplasms in other sites where pre-operative biopsy is possible and treatment can be planned based on their reports, biopsy is not recommended in salivary neoplasms, ${ }^{(8)}$ especially parotid because of the fear of tumour spillage and nerve injury. The only acceptable biopsy in a parotid tumour is superficial parotidectomy.

FNAC is a cheap, easy, simple and sensitive method for diagnosing salivary neoplasms and these salivary glands are easily accessible to FNAC. Hence, FNAC is being commonly used to diagnose salivary neoplasms.(9)

\section{But the disadvantages of FNAC are}

1. Since salivary neoplasms have the features like histological complexity and morphological variability, FNAC carries a significant risk of falsely diagnosing a benign tumour as malignancy or missing out a malignancy.
2. FNAC results alone would not determine the plan of management as even though the FNAC results are negative for any neoplasm, surgery can be done based on the clinical and radiological data available.(2)

So FNAC being a cheap, simple, outpatient procedure and sensitivity is higher, it can be used as a pre-operative investigation for diagnosing salivary neoplasms.

But the disadvantages are that it cannot be purely relied upon for diagnosis, as there is always a chance for either a wrong diagnosis or missing out a correct diagnosis as supported by our study. ${ }^{(10,5)}$

\section{REFERENCES}

1. Orell SR, Sterrett GF, Whitaker D. Fine needle aspiration cytology. $4^{\text {th }}$ edn. Philadelphia: Elsevier 2005.

2. Cuschieri A, Steele RJC, Moosa AR. Essential surgical practice: higher surgical training in general surgery. $4^{\text {th }}$ edn. London: Hodder Arnold 2002.

3. Townsend Jr CM, Beauchamp RD, Evers BM. Sabiston's textbook of general surgery. 19th edn. Elsevier 2012.

4. Brunicardi F, Andersen D. Schwartz principles of general surgery. $9^{\text {th }}$ edn. McGraw-Hill Professional 2009.

5. Young JE, Archibald SD, Shier KJ. Needle aspiration cytologic biopsy in head and neck masses. Am J Surg 1981;142(4):484-489.

6. Eneroth CM, Zajicek J. Aspiration biopsy of salivary tumors, morphologic studies on smears and histological sections from 368 mixed tumors. Acta Cytol 1966;10:440-454.

7. O'Dwyer P, Farrar WB, James AG, et al. Needle aspiration biopsy of major salivary gland tumors. Its value. Cancer 1986;57(3):554-557.

8. Zajicek J, Eneroth CM, Jakobsson P. Aspiration biopsy of salivary gland tumors. Acta Cytol 1966;20:35-41.

9. Eneroth CM, Zajicek J. Aspiration biopsy of salivary gland tumors. IV. Morphologic studies on smears and histologic sections from 45 cases of adenoid cystic carcinoma. Acta Cytol 1969;13(2):59-63.

10. Buckland JR, Manjaly G, Violaris N, et al. Ultrasoundguided cutting-needle biopsy of the parotid gland. J Laryngol Otol 1999;113(11):988-992. 